\title{
EVENT EXPERIENCES THROUGH THE LENS OF ATTENDEES
}

\author{
WEI LIU, BEVERLEY SPARKS, AND ALEXANDRA COGHLAN \\ Department of Tourism, Sport and Hotel Management, Griffith Business School, \\ Griffith University, Gold Coast, Australia
}

\begin{abstract}
This study takes a holistic approach to investigating customer experience at a food and wine event. Drawing on an ecosystem concept from service design and the concept of cocreation of value, the authors develop a conceptual framework to capture the complexity of customer experience. Using photo elicitation methodology to combine customers' in situ experience as reflected in photos, narratives, and attribute ratings, the authors identify five main themes, of which sensory experience, discovery, and entertainment/fun demonstrate a high level of impact on customer experience. The photo elicitation method provides insight into fluctuations in customers' emotions over a 1-day period and captures various customer experiences, from ordinary to extraordinary, which created the overall customer experience at the event. Results show that both positive and negative customer experiences are affected by the ecosystem, especially with respect to whether components of the system are functioning in a harmonious manner. The study's findings demonstrate that when designing event programs, event management should be aware of the importance of balance within the ecosystem.
\end{abstract}

\section{Key words: Photo elicitation; Event experience; Cocreation}

\section{Introduction}

Customer experience is a major component of service industries, especially the event industry, and has strong links to important variables such as customer satisfaction and loyalty (e.g., Hosany \& Witham, 2009). Customer experience can be influenced not only by elements within the service provider's control (e.g., physical environment, service employees), but also by elements that are beyond the service provider's control (e.g., the customer's previous experience, interactions with fellow customers, fluctuation in the customer's moods) (Verhoef et al., 2009). Therefore, it is important to understand the customer's experience from a holistic perspective that extends to the various contextual and individualized aspects of an event. However, most research into event experiences applies conventional techniques that rely on retrospective evaluations of specific event attributes, with associated memory and recall issues (e.g., Getz, 2012, 2013). In addition, these techniques most commonly adopt 
an etic approach, with the parameters of the study dictated by the researchers and/or event management (e.g., D. L. Morgan, 1998; Venkatraman \& Nelson, 2008).

Both the retrospective nature of the data and the etic approach of the research can be problematic in capturing the dynamic aspects of customer experience. In particular, they may not provide a sufficiently rich, textured understanding of the event that is required to revitalize events in the later stages of the product life cycle, or to ensure the competitive advantage of events in an increasingly crowded sector (Boo \& Lu, 2015; Getz, 2012). Therefore, this study overlays an emic approach (Lett, 1990) onto conventional survey-based data to capture the in situ customer experiences at the more micro and momentary levels. It uses a combination of prior research results to generate event attributes and other recognized measures of customer experience and adds these to a photo elicitation with narratives approach that allows respondents to generate their own, individualized data regarding their event experience. Such an approach makes a significant contribution to understanding how consumers create value from an event, as the researchers are able to uncover the personal meanings and feelings participants assign to their experiences. The main research question to guide this study was: How do people interact with the event ecosystem as part of the cocreative process of customer experience? Our research provides the basis for building a conceptual model of the event experience by integrating an "ecosystem design" and the cocreation approach (Vargo \& Lusch, 2004) that potentially contributes to the ongoing sustainability of such events.

\section{Literature Review}

\section{Holistic Perspective of Customer Experience}

The creation and delivery of customer experience has occupied a central role in the service industry (Badgett, Moyce, \& Kleinberger, 2007). However, understanding and managing customer experience is challenging, as "experience” is a broad term encompassing many variables related to the customer's sensory experience, feelings during the experience, and concurrent and subsequent appraisals. Researchers argue that customer experience originates from a set of interactions between a customer and a product or the service provider, which involves the customer's responses at different levels: cognitive, affective, emotional, social, and physical (Gentile, Spiller, \& Noci, 2007).

Importantly, customer experience is created and influenced by elements that are both within and beyond service providers' control (Verhoef et al., 2009). Therefore, customer experience is best understood from a holistic perspective (Gentile et al., 2007). This holistic conceptualization of the customer experience implies that the research of customer experience needs a broader understanding of the multiple factors that affect the customer's experience (Verhoef et al., 2009).

To encourage desired customer experiences, service providers must create the right setting and environment with elements that enable customers to connect with the service in a personal, memorable way (Schmitt, 1999), leading to customer satisfaction and ultimately customer loyalty (Gupta \& Vajic, 2000). Prior researchers have proposed a number of conceptual frameworks to depict the composition of customer experience. For example, Bitner (1992) developed the framework "servicescape" to understand the impact of the physical environment on customers, employees, as well as the interactions between them. This framework implies that a business creates the opportunity (or the setting) for an experience by orchestrating a series of elements, such as the physical environment and human interactions, while the customers use these resources to create meaningful experiences. In another study, Walls, Okumus, Wang, and Kwun (2011a) offered a framework to better understand this construct in a hospitality and tourism context. The proposed framework demonstrates the multidimensional facets of the consumer experience. More importantly, customers live the experience by adding different individual and situational variables, such as motivations, past experiences, and individual personalities, to make the experience personal, meaningful, and memorable.

The service design literature offers an appropriate way to better conceptualize the complexity of this type of orchestration of an event offering (e.g., Polaine, Løvlie, \& Reason, 2013). Taking a holistic perspective of customer experience, many service 
design scholars depict the service offering as an ecosystem (e.g., Akaka, Vargo, \& Lusch, 2013), comprising various components that combine to lead to a positive or negative customer experience. In the present study, the experience selected for study — food and wine event-occurred within the ecosystem illustrated in Figure 1, which depicts how an event organizer delivers the event offering to the customer through event components that include celebrity chefs, vendors/products, volunteers, paid (add-on) activities, and venue.

Importantly, within the event ecosystem customers often have no direct contact with the event organizer, whose role is to create and prepare the tools and infrastructure that support the different components in the ecosystem in delivering a good service experience to customers (Polaine et al., 2013). The customer experience within the ecosystem is predominantly influenced by a set of communications and interactions between customers and event components at different touchpoints. Once a customer enters the event, sensory elements at the event venue such as lighting, sounds, temperature, other customers, or the service provided by event staff or volunteers start to affect the customer's experience. Customers are also likely to have varying feelings about the experience, such as pleasant or unpleasant. Hence, investigating customer experience by portraying the service offering as an ecosystem and demonstrating how various components influence the customer's experience through the ecosystem may help generate new knowledge of customer experience from a holistic perspective and add in-depth insight of customer experience enhancement for businesses.

This approach can also help in understanding the value creation process in events. Value creation has become an increasing concern for the distinctiveness and competitiveness of goods and services. As value creation occurs between the service provider and the customer, it is closely linked to the cocreative process. The outcomes rely on the relationships formed between the service provider, or event organizer, and the customer, through an individualized, meaningful interaction through direct experience (Prahalad \& Ramaswamy, 2004). This perception represents a shift from a transactional understanding of value creation to a relational approach

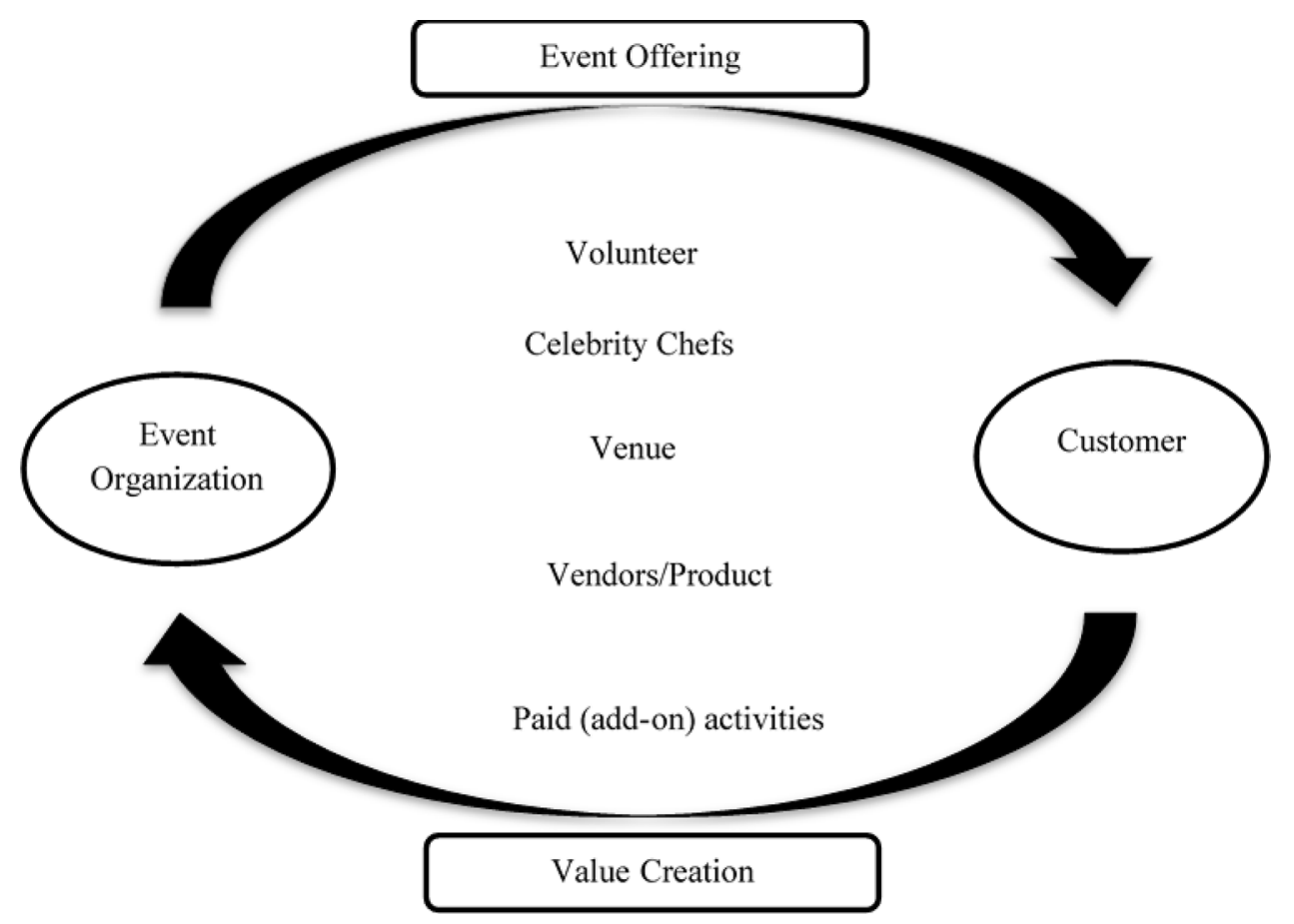

Figure 1. A basic service ecosystem of a food and wine event. Adapted from Polaine et al. (2013, p. 80). 
facilitated by the service context (Vargo \& Lusch, 2004). Value creation in the event sector occurs within a given physical space, bringing together a number of components in a set program that, broadly speaking, fosters face-to-face social interactions, activities, learning, and entertainment, thereby providing for a multitude of relational, cocreated value opportunities (Crowther \& Donlan, 2011). Understanding these opportunities for value creation requires comprehending this cocreative process as it operates within event customer experiences.

\section{Previous Research to Investigate Customer Experience}

Understanding the customer experience from a holistic perspective has proven to be a complex undertaking. Many researchers who espouse a holistic approach have done so from a conceptual rather than empirical basis (e.g., Verhoef et al., 2009; Walls et al., 2011a). Other researchers have adopted an attribute-based approach where aspects of the experience to be captured are determined by researchergenerated questions (e.g., Hosany \& Witham, 2009; Walls, Okumus, Wang, \& Kwun, 2011b). However, some investigators challenge these existing techniques, arguing that they can be problematic in capturing the dynamic aspects of customer experience. Customer experience is a dynamic process rather than a static state in that a customer encounters a service or product and interacts with service personnel or other customers (e.g., Getz, 2010; Van Winkle \& Falk, 2015).

Traditional techniques, in particular the attributebased approach, are normally based on a researcherdriven agenda and assumptions and therefore may minimize the cocreation aspect of customer experience, "in which a company provides the consumer with the basic platform and raw materials that are then being used by the consumer to mould and obtain his/her own experience" (Gentile et al., 2007, p. 397). Thus, an attribute-based approach could present difficulty in gaining a better understanding of the momentary occurrences that comprise an individual's experience. More importantly, a customer's cognitive and affective responses change throughout the experience journey (Nawijn, 2011) and may be better captured with in situ research methods.
Tremendous research effort has been focused on motivation and satisfaction rather than the experience. For instance, empirical evidence is found in the literature (e.g., Axelsen \& Swan, 2010; Baker \& Crompton, 2000; Lee, Lee, Lee, \& Babin, 2008; M. C. Mason \& Paggiaro, 2012; Yuan \& Jang, 2007) identifying a number of service attributes that may affect attendees' experiences, such as quality of event program, service quality by staff members/ volunteers, quality and availability of auxiliary facility, food quality, souvenirs, convenience and accessibility, and information availability. Why people attend events and the links between motivation, satisfaction, and behavior is another popular research area into event experience (Getz \& Page, 2016; Li $\&$ Petrick, 2006). The most common event motivations identified from the literature (e.g., Bowen \& Daniels, 2005; Kim, Uysal, \& Chen, 2001; P. Mason \& Beaumont-Kerridge, 2004; Savinovic, Kim, \& Long, 2012; Van Zyl \& Botha, 2004; Yuan, Cai, Morrison, \& Linton, 2005) include fun, social interaction, doing things with family, novelty, food and beverage, and knowledge/education.

Although previous studies have demonstrated valuable insights when investigating event experiences, an understanding of the in situ experience events remains limited. As a result, some researchers (e.g., Getz \& Page, 2016; M. Morgan, 2008) call for more research using creative and experientialbased methods rather than conventional surveys to investigate customer experience. One such method to gain depth of insight to the event customer's experience is photo elicitation.

\section{The Photo Elicitation Approach}

One way to tackle some of the issues raised in the preceding discussion is to adopt an emic approach, which might build upon more traditional, etic approaches. An emic approach stems from notion that an insider can provide insights otherwise inaccessible to the researcher. The emic approach specifically values the customers' (in this case, event attendees') self-understanding and makes few, if any, a priori judgments about the boundaries of the phenomena under investigation or the best constructs to use in understanding those phenomena (cf. Harris, 1976). That is, the researcher deliberately does not impose 
his or her view of the phenomena onto the way the data are collected. An emic approach is also more likely to value the importance of a holistic method, be interested in the interconnections within the system, and employ wide-ranging observations of a single case study, rather than snapshots of multiple cases for comparative purposes. A number of methods are used to capture emic knowledge, and all have in common that they allow the respondent to guide the direction and content of the data collected. Some examples of these methods include ethnographic fieldwork/participant observation, journaling, unstructured interviews, and, of interest here, photo elicitation.

Photo elicitation is a visual, qualitative research technique (Harper, 2002). The advantages of introducing photographs into the research setting to trigger memories and facilitate recall have been well documented (e.g., Pink, 2013; Scarles, 2010; Tinkler, 2013). For instance, photographs become an instrument within the research process as greater emphases lie on subjective meaning and the practices and processes behind the creation of the image (Scarles, 2011). Through respondents' responses to images, photographs provide the opportunity to explore social and personal meanings as well as values (Bignante, 2010). Therefore, this type of approach is interesting not only because of the visuals themselves, but because it can be combined with other techniques such as interviewing, focus groups, researcher or respondent diaries, and so forth, as a means of furthering communication and opportunities for respondents to express and explore experiences of particular research phenomena.

One study that combines the photo elicitation technique and "servicescape" concept was conducted by Venkatraman and Nelson (2008). In this study, participants took photographs of their experience as they visited Starbucks, and later discussed their experiences with the researchers. The researchers found that it is the experience within the servicescape that matters as much, if not more than the core product itself. In another study, Matteucci (2013) used images collected by the researcher with in-depth interviews and participant observation to identify the more intimate aspects of tourism experiences. The results demonstrated that in a number of ways, photo elicitation is a valuable tool to investigate tourists' embodied experiences. A photo elicitation approach successfully prolongs interviews, triggers personal experiences and memories, and most importantly, gives the researcher a tool to expand on questions so that dimensions of people's lives may be unveiled. In another study, the researchers invited hotel guests to take pictures during their stay and used these participant-generated images to investigate hotel design elements from customers' perspectives (Pullman \& Robson, 2007). The results showed that a photo elicitation approach provides insights beyond those obtained from traditional methods, such as surveys and interviews. More importantly, the study showed that by using participant-generated images the photo elicitation method can be particularly suited to investigating customer experience, because the customer uses a camera to record impactful moments that can be discussed later with the researcher. However, to date photo elicitation has not been extensively used in event experience research.

\section{Methodology}

\section{Event Context}

This study sought to understand customer experiences at an indoor food and wine event held in late 2014 as part of an overarching event conducted in various Australian capital cities (Brisbane, Melbourne, Sydney, and Perth). At each location, the show runs over a 3-day weekend from Friday to Sunday, and most individuals attend the show for 1 day. In the 1-day period, the event included food and wine displays, celebrity chef demonstrations, cooking classes, coffee-making classes, and winetasting master classes. This broad offering allows for the capture and comparison of many experiences across the whole event period.

\section{Participants}

To be eligible for this study, participants needed to be a day ticket holder to the event. To assist with recruitment of participants, the event organizer sent e-mail invitations on behalf of the researchers to a sample of ticket holders listed in the company's database. Twenty-six event ticket holders 
expressed interest in participating in the study, and 25 event attendees completed the study. Of the 25 respondents, 21 were female and 4 were male. Respondents 45-54 years old who worked full time comprised the largest age group. This sample profile is reflective of the event's market, which is predominantly female attendees and between 25 and 64 years old. Table 1 shows the demographic distribution of all study participants.

\section{Procedure}

Ethical approval was obtained from the researchers' university to conduct the study and the event organizers gave permission for the research to be undertaken at the event. Two weeks prior to the study, the event organizer distributed an invitational e-mail containing a link to register an interest in participating in the study. Respondents activating the link received a detailed information sheet about the study and then, if they were interested, registered to join the study. Once the researcher received a person's registration information, the researcher telephoned the participant and went through the study instructions to confirm participation and make sure the participant understood the research purposes and processes.

Table 1

\begin{tabular}{lr}
\multicolumn{2}{l}{ Participant Demographics $(N=25)$} \\
\hline Variable/Category & Frequency \\
\hline Gender & \\
$\quad$ Male & 4 \\
Female & 21 \\
Age & \\
18-24 & 1 \\
25-34 & 6 \\
$35-44$ & 7 \\
45-54 & 10 \\
$55-64$ & 1 \\
Employment status & \\
Working full time & 14 \\
Working part time & 6 \\
Full-time student & 3 \\
Home duty & 2 \\
Past attendance & \\
Never & 11 \\
Once & 2 \\
Three times & 2 \\
Four or more times & 10 \\
\hline
\end{tabular}

During this study, participants used their smartphones to take photos of anything that they felt contributed in some way to their customer experience (good or bad) at the 1-day food and wine show. Within 3 days of attending the event, each participant sent back 10 self-selected photos that best represented his/her experiences at the show. Photos were then incorporated into an online survey (Qualtrics) that participants completed afterwards.

\section{Instrument}

The survey contained a mix of open-ended questions to capture the meaning participants ascribed to each photo, a Likert-scale measure of valence associated with the experience depicted in the photo, and a researcher-generated list of elements that prior research suggests contribute to the experience. Participants answered a series of questions about the photo experiences as part of an exploration of their feelings and thoughts about the food and wine show. First, each photo was followed by an openended question asking the participant to reflect on the motivation for taking the picture. This question was followed by a single question designed to measure the participant's emotional valence (positive or negative) at the time: "Reflecting back on the moment captured in the photo, to what extent did you feel the experience was $(1=$ very negative to 5 = very positive)?"

Next, to better understand what caused participants' momentary feelings, the following question was asked: "What elements contributed to your feelings about the moment captured in the photo?" Participants could choose more than one answer from a list of elements generated in previous focus group interviews and from the event organizer's business knowledge. Two months before the actual event, the researchers conducted five focus group interviews $(N=20)$ with previous event attendees to assist in setting a foundation of what experiences people normally had at this type event. The event company also conducted focus group interviews with previous event attendees to get a better understanding of customers' needs and what elements might be missing from current event offerings. The two sets of focus group results made clear that several rational and emotional drivers brought customers to this event. The final list included: 
- Bonding with family and friends

- Discovering new trends of food and wine

- Having fun

- Feeling inspired about food and wine

- Interacting with food and wine experts

- Having a positive sensory experience (e.g., smell, taste, etc.)

- Having a multicultural food experience

- Other (participant defined)

These items were incorporated into the survey and repeated for each of the 10 photos.

Additional information collected included overall satisfaction $(1=$ very dissatisfied to $5=$ very satisfied), likelihood to recommend the event to others ( 1 = very unlikely to $5=$ very likely), and likelihood to return to the event the following year $(1=$ very unlikely to $5=$ very likely). The survey also collected information about demographics concerning gender, age, employment status, and show-visit characteristics (e.g., number of previous visits, show-visit date, and companions attending the event).

\section{Findings}

Visualizing the Event Components:

Content Analysis of Photos

First, the researchers performed a content analysis of all 246 images to identify the focal themes from them, constructing a coding frame inductively from the broader range of photos. In coding the photos, the researchers first reviewed the photo content and classified it based on the dominant foreground focus of the image. They then checked the event program to determine whether the photo content related directly to paid (add-on) activities, such as wine tasting masterclass or cooking masterclass.

Two members of the research team conducted the coding simultaneously and then discussed any disagreements until reaching consensus on the category. This process yielded a high correspondence of coding ( $>90 \%$ ). Through the content analysis, seven categories were identified from the total 246 pictures: vendors, paid (add-on) activities, people, products (food), venue, products (beverage), and merchandise. Detailed category definitions and example images appear in Table 2.

As Table 2 shows, the top three themes of photographs focus on vendors, followed closely by paid (add-on) activities, such as a series of master classes for wine appreciation or cooking demonstrations that were put together by the event organizer, and images with people, such as photos of participants by themselves or with their friends/family at the show.

The content analysis of participants' photographs illustrates that in the ecosystem of the event in this study, the event components include vendors, paid (add-on) activities, products (food and beverage), celebrity chefs, and venue.

\section{Understanding Customer Experience: Content Analysis of Photo Narratives}

The main objective of this research is to better understand the nuances associated with the personal process of customer experience at an event. Thus, while the photographic images are helpful in understanding what objects matter to people, it is the meaning individuals assign to these objects that is really important for understanding customer experience. To gain insight into how people construct their experiences, this section relies on the narratives written by the respondents to elaborate what lies behind the photo images.

NVivo software was used to complete the data analysis process. Two research team members independently reviewed the narratives for significant phrases or sentences and applied an open-coding process using individual participants' comments that pertained to their event experiences. This process yielded a high correspondence of coding (>90\%). Disagreements $(<10 \%)$ were discussed until the researchers reached consensus on the themes. Five main themes were identified through the coding of the narratives associated with each photo. In order of frequency, these were: sensory experience, discovery, entertainment and fun, physical environment, and human interaction. Table 3 provides the list of the five main themes, along with descriptions, frequencies, and illustrative quotes.

In the following discussion, each of the themes presented in Table 3 is further unpacked to elaborate and demonstrate what customer experiences were captured at the food and wine event.

Sensory Experience. The first, and most salient, theme is classified as sensory experiences associated 
Table 2

Categories, Definitions, and Example Images

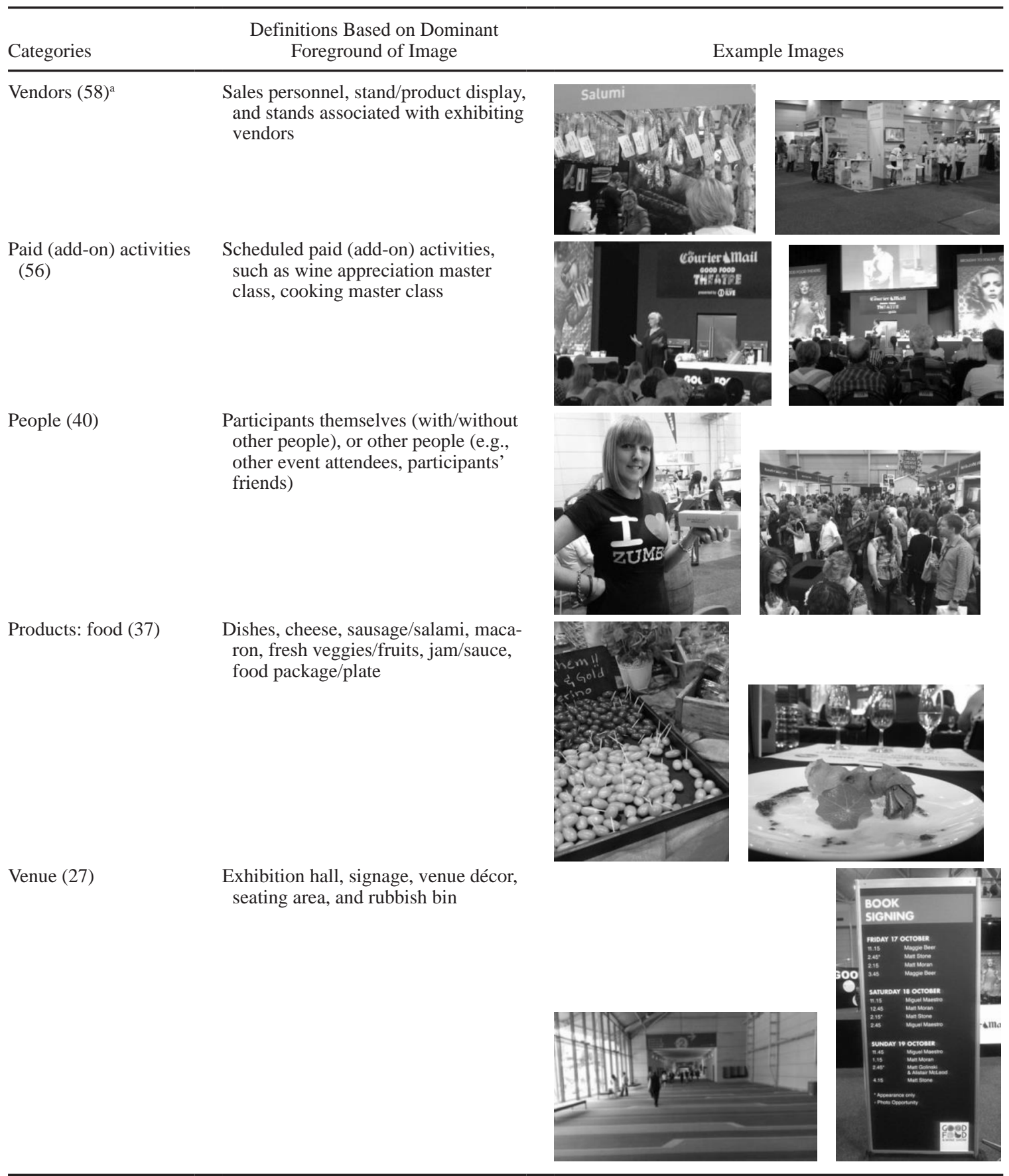

(continued) 
Table 2 (Continued)

\begin{tabular}{ll}
\hline $\begin{array}{c}\text { Definitions Based on Dominant } \\
\text { Foreground of Image }\end{array}$ & $\begin{array}{c}\text { Alcoholic drinks, such as wine, cock- } \\
\text { tails, beer; or nonalcoholic drinks, } \\
\text { such as coffee, tea; and beverage } \\
\text { containers, such as wine glasses, } \\
\text { coffee cup }\end{array}$ \\
Products: beverage (16) & Shopping trolley, purchased goodies, \\
and giveaway goodies &
\end{tabular}

${ }^{\mathrm{a}}$ The numbers in parentheses indicate the number of images in that category.

with people's five senses: sight, smell, taste, sound, and touch. At the food and wine show, participants have countless opportunities for sampling food and wine, smelling the aroma of coffee and tasting, sampling cheese, and tasting beer and wine. Within this theme, the largest category of the commentary focuses on experiences associated with the taste of food and/or beverages, for example, "OMG! This was fantastic and yummy.” Additionally, findings from the analysis indicate that the visual aspects of food and beverages, such as the color, arrangement, or design of the product package, also often attract participants' attention. In some instances, participants' sensory experiences arise from more than one source, such as with the combination of the taste and the visual appeal ("They look delicious and have to say they tasted fabulous") or the enjoyment from both smell and taste ("These prawns ... smelt fantastic. Beautiful looking dish!”). For some participants, the stimulation of one sense, such as sight, might activate another sense, such as taste ("I found it very appealing and wanted to eat them all as they looked great”).
The research findings show that all 25 participants consistently mention sensory experiences, illustrating that sensory experience at this type of event is very important to people. Notably, the narratives coded as sensory experiences also contain many references to feelings of excitement, enjoyment, and fun. As the quotes show, participants frequently describe their sensory experiences using highly positive emotional words such as "fabulous," "fantastic," and "appealing." The elicited positive emotions sometimes have flow-on effects to customers' behaviors, such as purchasing ("I loved the name, the taste and the size, and I ended up buying a dozen!") or sharing with friends and family ("This is yummy and different! I took the picture to show friends").

Discovery. A major theme emerging among participants is the discovery dimension of people's experiences. One of the most important elements of this food and wine show is the introduction of new trends of food and wine products, technology, and recipes. The findings reveal that the discovery 
Table 3

Main Themes, Frequency, and Example Quotes Identified From Image Narratives

\begin{tabular}{|c|c|c|c|}
\hline Themes & Frequency & Description & Example Quotes \\
\hline Sensory experience & 104 & $\begin{array}{l}\text { Any comments about par- } \\
\text { ticipants' sensory experiences } \\
\text { related to taste, visual sight, } \\
\text { smell, and sound }\end{array}$ & $\begin{array}{l}\text { This was the best cheese tasting I've ever experienced. } \\
\text { The smell of the coffee was amazing! } \\
\text { I love the range and smell of all of the salamis they } \\
\text { had available. }\end{array}$ \\
\hline Discovery & 95 & $\begin{array}{l}\text { Any comments about discovery } \\
\text { of new trends of food and wine, } \\
\text { learning new things about food } \\
\text { and wine, feeling inspired by } \\
\text { food and wine experts }\end{array}$ & $\begin{array}{l}\text { This is the first time in my life I see this blend in } \\
\text { another brand of wine. So it was exciting! } \\
\text { Excited about learning how to cook a Barilla pasta } \\
\text { sauce from scratch. }\end{array}$ \\
\hline Entertainment and fun & 37 & $\begin{array}{l}\text { Any comments about fun, } \\
\text { excitement, enjoyment, and } \\
\text { memorability }\end{array}$ & $\begin{array}{l}\text { The chefs are always extremely entertaining and } \\
\text { inspiring-great fun and thoroughly enjoyable. } \\
\text { It was just funny Miguel Maestre came along at that } \\
\text { time to entertain the crowd! }\end{array}$ \\
\hline Physical environment & 36 & $\begin{array}{l}\text { Any comments about specific } \\
\text { dimensions of physical settings, } \\
\text { including program logistics, } \\
\text { venue layout, and signs and } \\
\text { symbols }\end{array}$ & $\begin{array}{l}\text { One half of the venue was crowded like this, yet in } \\
\text { other areas there was open space going to waste. } \\
\text { This was } a \text { well set up workshop, which would run } \\
\text { through making different coffees using a Nespresso } \\
\text { machine. }\end{array}$ \\
\hline Human interaction & 36 & $\begin{array}{l}\text { Any comments about interac- } \\
\text { tions with celebrity chefs, } \\
\text { vendors, and also interactions } \\
\text { with other customers attending } \\
\text { the show on the same day }\end{array}$ & $\begin{array}{l}\text { I liked being able to talk to people about new products. } \\
\text { It was so much fun because that gave me the chance } \\
\text { to talk to winemakers about it, learn and exchange } \\
\text { really nice and even funny conversations. }\end{array}$ \\
\hline
\end{tabular}

experience in the event encompasses a mixture of learning of new trends and products of food and wine, learning new things about food and wine (e.g., cooking methods, recipes, etc.), and being inspired by food and wine experts. As the narratives indicate, feelings of excitement and enjoyment about finding something new permeated the narratives ("This is the first time in my life I see this blend in another brand of wine so it was exciting”). The narratives also demonstrate that once participants discover something new or different, they tend to take pictures and share with family and friends ("Love finding new wines and wanted to share with friends").

This event also offers a variety of master classes that give participants unique opportunities to learn new information about eating and drinking. As the quotations show, the learning experience is delivered to customers through both passive and active learning experiences. The analysis reveals that participants become more active and engaged and reach a higher level of enjoyment when their learning experiences are stimulated by their own needs and interests. Additionally, the learning experiences are more enjoyable for participants when the program hosts are being entertaining and informative.

Entertainment and Fun. Findings illustrate that entertainment and fun are central to customer experience in the context of a food and wine event. Respondents normally associated the fun and entertainment dimension of customer experience with interacting with celebrity chefs or exhibiting vendors ("The best part of the show - the chefs are always extremely entertaining and inspiring - great fun and thoroughly enjoyable" or "It was so much fun because that gave me the chance to talk to winemakers about it, learn and exchange really nice and even funny conversations"). As the participants' comments show, their entertainment and fun experiences resulted in a mixture of enjoyment and excitement.

Further analysis revealed other aspects associated with participants' entertainment and fun experiences, including the discovery of something new ("My first cronut! Have heard a lot about this 'food' and was pleased to have the opportunity to try it”), 
having a positive sensory experience ("This was the best cheese tasting I've ever experienced”), and bonding with friends ("Love this picture with my friend! We go to the show every year! It’s a special thing we like to do").

Physical Environment. The content analysis also illustrates that customer experience at the event can be shaped by the surrounding physical environment. Participants mention a number of specific dimensions of the physical environment that affect their experiences at the show, including program logistics, venue layout, and signs and symbols. Mostly, customer experiences are positively influenced by the event/program logistics ("Reflects positively on the logistics" and "The atmosphere was positive and the session began very well"). A few participants also appreciated the indoor signage ("Frustration at hand-held literature but large-scale signage inside the event was useful"). Although quite limited in number, some negative comments fell into this category, in which participants described obstructions to their experiences at the show. Predominantly, the poor layout and overcrowdedness appear to have elicited very strong negative feelings ("Overcrowding ... significantly detracted from the experience" and "It was too crowded! I missed the whole cheese section.... Really poor layout”).

Human Interaction. The qualitative analysis evidenced that the dimension of human interaction is crucial to participants' experiences. Two types of human interaction were identified in the analysis: (1) interactions with service providers, including celebrity chefs, performers, and vendors, and (2) interactions with other customers attending the show on the same day. Predominantly, interaction with service providers contributed positively to participants' overall experiences. Three characteristics of exhibitors affected participants' interaction experiences positively: excellent customer service skills, great knowledge of their own products, and entertaining personalities. In addition to interaction with service providers, participants also mentioned how other customers at the show influenced their experiences, both positively and negatively ("This was a very nice fellow ... a and took us under his wing to show us some of the excellent wines showcased at the show" and "Those trolleys and the people driving them were really annoying”).

To sum up, the content analysis of the narratives associated with participants' photographs illustrates that customer experience at the food and wine event (the ecosystem of current study) mainly comprises five dimensions: sensory experience, discovery, entertainment and fun, physical environment, and human interaction. Also, the impacts of various event components on customer experience in the ecosystem are apparent in each dimension. For example, customers' sensory experience is influenced by the venue layout, flow control, and range and quality of the exhibited products. In addition, as shown in Table 4, participants cite that the top three elements contributing to their experiences depicted in photos are (by frequency order) having fun (114), having a positive sensory experience (108), and interacting with food and wine experts (96).

\section{Personal Factors}

In addition, the content analysis identified several personal factors customers bring into the event

Table 4

Valence Evaluations and Contributing Elements

\begin{tabular}{|c|c|c|c|c|}
\hline Contributing Elements & $\begin{array}{l}\text { Negative } \\
{[N(\%)]}\end{array}$ & $\begin{array}{l}\text { Neutral } \\
{[N(\%)]}\end{array}$ & $\begin{array}{l}\text { Positive } \\
{[N(\%)]}\end{array}$ & $\begin{array}{c}\text { Total } \\
{[N(\%)]}\end{array}$ \\
\hline Bonding with family and friends & $2(8)$ & $0(-)$ & $51(9.60)$ & $53(9.25)$ \\
\hline Discovering new trends of food and wine & $3(12)$ & $2(11.76)$ & 80 (15.07) & $85(14.83)$ \\
\hline Having fun & $0(-)$ & $4(23.53)$ & $110(20.72)$ & $114(19.90)$ \\
\hline Feeling inspired about food and wine & $0(-)$ & $2(11.76)$ & $64(12.05)$ & $66(11.52)$ \\
\hline Interacting with food and wine experts & $6(24)$ & $3(17.65)$ & $87(16.38)$ & $96(16.75)$ \\
\hline Having a positive sensory experience (e.g., smell, taste, etc.) & $0(-)$ & $4(23.53)$ & $104(19.59)$ & $108(18.85)$ \\
\hline Having a multicultural food experience & $0(-)$ & $1(5.88)$ & $32(6.03)$ & $33(5.76)$ \\
\hline Other & $14(56)$ & $1(5.88)$ & $3(0.56)$ & $18(3.14)$ \\
\hline Total $N$ & $25(100)$ & $17(100)$ & $531(100)$ & $573(100)$ \\
\hline
\end{tabular}


ecosystem that play important roles in shaping their experiences at the show, such as show-visit company, personal interests and needs, and involvement in activities. As illustrated above, when participating in paid (add-on) activities customers indicate a higher level of enjoyment if their personal interests and needs are met. These findings demonstrate that customers tend to cocreate their own unique experiences through a set of interactions between the various event components in the ecosystem and their personal characteristics.

\section{Cocreation Process of Customer Experience}

The customer narratives also illustrate that the cocreated customer experience involves the customer cognitively, emotionally, and behaviorally. The analysis indicated that customers regard this event as an opportunity to gain knowledge from experts about eating and drinking, to discover new trends in food and wine, and to bond with friends and family. Emotionally, customers tended to use words like "fabulous," "fantastic," or "exciting” when expressing positive feelings, and to use "dislike," "distracted," or "annoying” to convey negative feelings. In some cases, these positive feelings have flow-on effects to customer behaviors, such as purchasing the products or sharing experiences with friends and family.

\section{Outcomes: Evaluation of Valence}

Of further interest was whether the photographed customer experiences had positive or negative valence. Respondents' ratings of the valence of the experience represented in the photos comprised 209 positive, 12 neutral, and 25 negative evaluations. Although the positive and neutral valences are spread across all categories, the negative valence ratings are mainly associated with photographs of vendors, other people attending the show, and the venue of the show.

When rating the valence, participants also indicated what elements contributed to their feelings about the moment captured in the photo. Main elements of importance to positive experiences depicted in photos were (by frequency order) having fun (110), having a positive sensory experience (104), and interacting with food and wine experts (87). Among the 25 negative experiences, over half were caused by elements falling into the "other" category and included venue layout (6), vendor availability (4), program setup (3), and value for money (1). Table 4 summarizes what elements contributed to participants' positive, neutral, and negative experiences associated with all submitted images.

\section{Outcomes: Evaluation of Satisfaction and Behavior Intentions (Recommendation and Repeat Visitation)}

Finally, at the end of the self-report survey, participants rated their overall satisfaction with the event, the likelihood of recommendation to friends and family, and the likelihood of repeat visits. Table 5 summarizes the results. As the table shows, over $90 \%$ of the participants were very satisfied and satisfied with the event. Thirteen (52\%) are very likely to recommend the event to others, seven (28\%) are likely to recommend, five (20\%) are undecided or unlikely to recommend. Additionally, $16(64 \%)$ are very likely to revisit the event, and 4 (16\%) are likely to revisit the event.

Table 5

Satisfaction, Recommendation, and Repeat Visit Intention

\begin{tabular}{lc}
\hline Variable/Categories & Frequency (\%) \\
\hline Satisfaction & \\
Very satisfied & $13(52)$ \\
Satisfied & $10(40)$ \\
Neutral & $-(-)$ \\
Dissatisfied & $2(8)$ \\
Very dissatisfied & $-(-)$ \\
Recommendation & $13(52)$ \\
Very likely & $7(28)$ \\
Likely & $4(16)$ \\
Undecided & $1(4)$ \\
Unlikely & $-(-)$ \\
Very unlikely & \\
Repeat visit intention & $16(64)$ \\
Very likely & $4(16)$ \\
Likely & $3(12)$ \\
Undecided & $2(8)$ \\
Unlikely & $-(-)$ \\
Very unlikely & $25(100)$ \\
Total $N$ &
\end{tabular}




\section{Modeling the Customer Experience}

The extensive analyses of the photos, narratives, and self-report materials led to formulation of an integrative model to provide insight to the overall customer experience of the food and wine event (Fig. 2). For each component of the model, the shading of the box indicates whether the data were generated through an emic or etic approach. As Figure 2 highlights, the event components and personal factors that underlie the cocreative process were captured through an emic approach, which when combined with the event elements (i.e., an attributebased approach derived from prior research) then underpins the customer experience, attendee outcomes, and value creation for the event organizers.

As Figure 2 shows, customer experience in the present study comprises five key dimensions and is cocreated between event components in the event ecosystem and personal factors brought into the ecosystem by customers themselves. Our analysis also demonstrates that the created customer experience involves customer responses at three levels: cognitive, emotional, and behavioral. These customer responses will potentially generate future benefits for event organizers through attendees' purchase of vendors' food and wine products, sharing of event experiences with friends and family, visiting the event next year, and recommending this event to friends and family.

\section{Discussion}

This study captures the cocreation process of customer experience using an in situ holistic perspective, building an emic approach onto existing

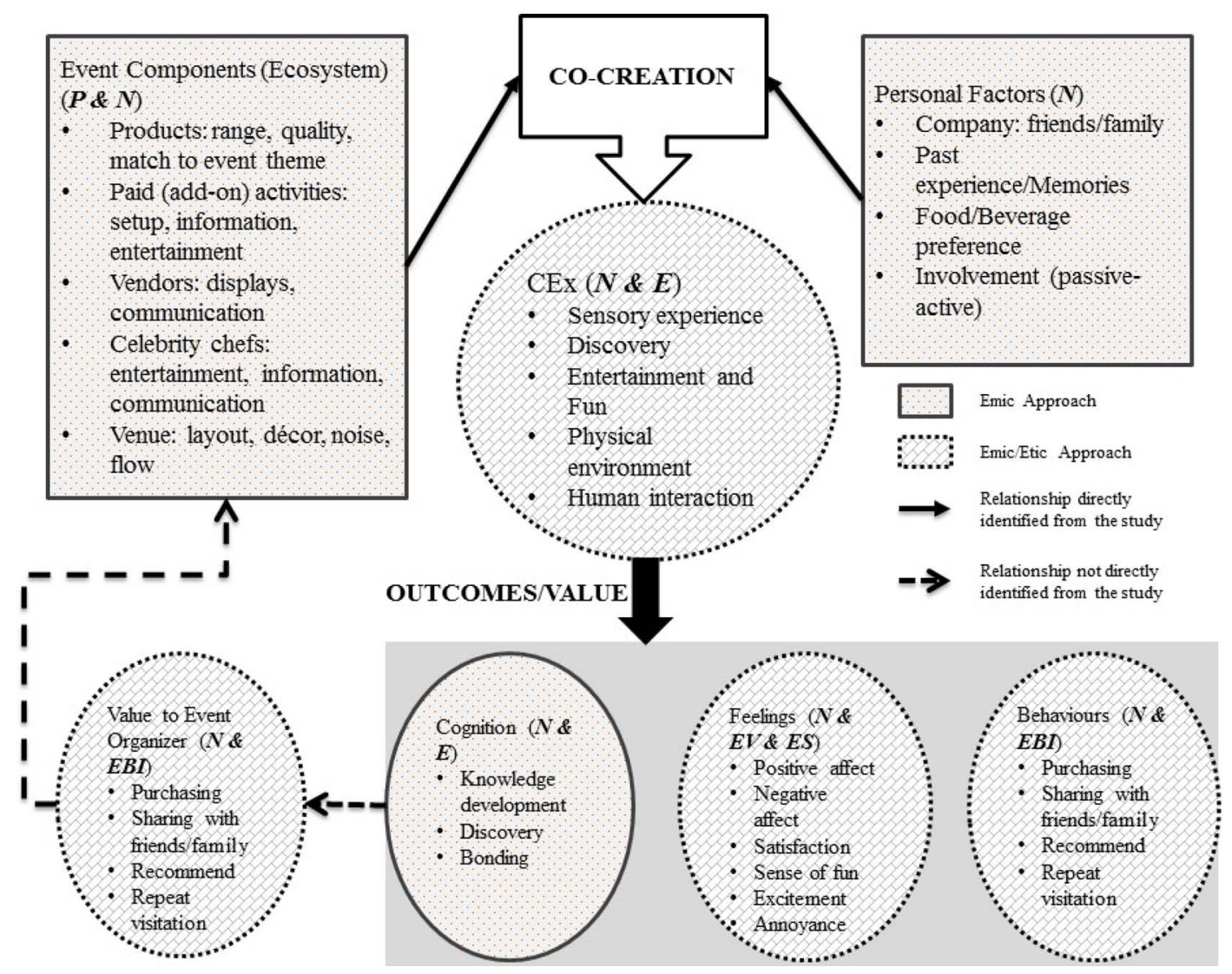

Figure 2. A conceptual model of customer experience creation at a food and wine show. $\mathrm{P}=$ photo; $\mathrm{N}=$ narratives; $\mathrm{E}=$ elements; EV = evaluation of valence; ES = evaluation of satisfaction; EBI = evaluation of behavior intentions. 
etic approaches. Furthermore, it employs the ecosystem concept of service design to capture the complexity and dynamic nature of event experience. We have focused on not only the event components but also the cocreated value for attendees of a food and wine event. The findings illustrate that the five key dimensions of customer experience identified from the study are cocreated with the event organizer by offering a variety of products, programs, and activities, and inviting celebrity chefs and vendors to participate in the event. These elements form an event ecosystem, into which the event attendees bring a range of personal factors to complete the cocreative process. This model emphasizes the unique combination of the business event organizer's role in creating the "stage" on which the experience occurs with the consumer's own unique personal factors, such as event-visit companions and previous experience or memories. No two customers have exactly the same experience. Each person has personal emotional responses as well as flow-on effects from responses to the service offerings.

This study offers a number of significant findings. First, by incorporating photo elicitation the investigation uses a novel methodological approach. Second, participants' responses demonstrate the salience of sensory experience, an opportunity for discovery, and being entertained and having fun. Third, findings show the diversity of moments of impact, ranging from ordinary to extraordinary. Fourth, results reveal the importance of balance within the event's ecosystem and its consequences for positive and negative experiences.

The novel photo elicitation methodological approach addresses the shortcomings of some eventrelated research (Crowther, Bostock, \& Perry, 2015). As this study illustrates, combining photos, narratives, and a survey provides an innovative research tool to investigate customer experience from the holistic perspective. This method can inform researchers, in participants' own voices, of what they are doing, thinking, and feeling, and how they perceive their social and physical environment that numerical tables or stand-alone interviews could not do. More importantly, this approach enables investigators to map out and model the cocreative process of customer experience, which furthers the understanding of the dynamic nature of food and wine events and the interrelationships of the components of value creation in a food and wine event context.

Of particular significance in the present study is the salience of sensory experience, the opportunity for discovery, and the availability of entertainment/fun moments to the individual's experience at the food and wine show, revealed through the triangulation of analyzing their photos, narratives, and self-reported elements. Not surprisingly, many participants spoke of the taste experience at the show, but perhaps more interesting were the findings of the importance of smell or aroma and the visual appeal of products. Also, our study demonstrated that sensory information not only could evoke positive emotional responses from customers, but also could facilitate other consumer behavior intentions, such as spending a longer time at the event or an exhibit, making purchases, or sharing the experience with friends and family (see also Agapito, Mendes, \& Valle, 2013; Walls et al., 2011b).

The second important dimension to customer experience is the opportunity of discovery (see also Yuan et al., 2005). In our study, participants loved to discover new things the show offered, such as new food and wine products, new recipes, or new cooking methods. In particular, they tended to experience a sense of inspiration or achievement from their discovery. Apart from the sensory and discovery experiences, participants indicated that they had lots of entertainment and fun moments at the show. Previous studies have demonstrated that this hedonic dimension is crucial to customer experience at such event (e.g., Hosany \& Witham, 2009).

Our investigation demonstrates that taking a photo in the moment and using a mobile method to capture experiences when they occur enables people to record all sorts of experiences, both ordinary and extraordinary (see also Walls et al., 2011a) and with transient to enduring outcomes. For example, people taking photos of themselves relaxing at the show is very "in the moment" and normally is regarded as an ordinary experience. The consequence of this type of experience might be quite transient and without long-lasting impact. In contrast, when participants report how they gained knowledge or learned techniques from celebrity chefs in a cooking class or learned about wine varieties and blends 
from wine vendors, the experience constitutes an extraordinary moment and has more enduring outcomes, such as the acquisition of new and longterm skills to use after the event.

The proposed customer experience model, which depicts the ecosystem of a food and wine event, provides managers and researchers with a framework for understanding and enhancing the elements of the overall customer experience at other festivals and leisure experiences. This model implies that instead of engaging in direct interaction with event organizers, event customers normally make direct contact with a series of event components, including vendors, celebrity chefs, event service staff, and volunteers cocreating their own narratives and experiences (see also Venkatraman \& Nelson, 2008). The evaluation of these interactions (either positive or negative) influences customers' evaluation of the event brand. For example, one participant in our current study visited the show on the last day and most of the stands were shut down or out of stock at $1 \mathrm{pm}$. She reported that she was very unsatisfied with her event experience and was very unlikely to recommend this event to her friends and family or to visit this event again the following year. This customer's experience underscores the importance of event companies' awareness that ensuring balance within the ecosystem is a key aspect of designing the event programs and has consequences for positive/negative experiences.

\section{Management Implications}

The major implication of this research for management is that event experiences are cocreated and entail multiple experiential dimensions. Bearing this in mind, managers should seek to create events that encourage customer interaction and involvement. Within the event ecosystem, there is ample opportunity to create activities that explicitly invite attendees to learn, discover, engage their senses, and have fun. By carefully considering each of the experience dimensions, event managers have an opportunity to further enhance the engagement and satisfaction with any event. One area where event attendees reported some dissatisfaction was to do with the interactions with vendors. Event managers could work with vendors to set out appropriate protocol on how to effectively engage with customers and potentially enhance customer experiences. Finally, managers could adopt a photo elicitation approach to collecting information about their events. This information can provide rich insights as well as useful information for applying for funding for future events.

\section{Conclusions and Future Research}

By employing the real-time photo elicitation technique, this study provides a foundation for a better and deeper understanding of customer experience. Photo elicitation offers an unobtrusive, engaging, and inspiring opportunity to communicate about customer experience (Petermans, Kent, \& Van Cleempoel, 2014), and combining the photo elicitation design with additional survey items assisted in understanding the multifaceted nature of experience. The method, although requiring a certain level of commitment by the participant, was well received and all people who enrolled in the study completed the task with detailed narratives, leading us to conclude that the method is well suited to understanding experiences at events. Of course, future researchers should be aware of the wide range of ethical issues, especially related to seeking permission from event organizers and respecting participants' privacy. Although future research might try to enlarge the sample size, such an increase could make the data analysis process quite time consuming, owing to the nature of a photo elicitation study.

In this study, people were given the freedom to photograph anything (good or bad) at the event that contributed to their experiences. Future research could encourage participants to take photos in the time sequence-from the moment they enter the event until the moment they walk out of the eventto depict their experience journey. In addition, future research could investigate the different effects of components of the ecosystem on the cocreative process and how different dimensions of customer experience influence the different emotions or behaviors people have at the event. In addition, future research could use complementary methods (e.g., ESM) to further understand the in situ experiences people have as part of the cocreative process. 


\section{Acknowledgment}

We acknowledge the support of the Griffith Institute for Tourism, Griffith University in assisting with financial support for the development of the article.

\section{References}

Agapito, D., Mendes, J., \& Valle, P. (2013). Exploring the conceptualization of the sensory dimension of tourist experiences. Journal of Destination Marketing \& Management, 2(2), 62-73.

Akaka, M. A., Vargo, S. L., \& Lusch, R. F. (2013). The complexity of context: A service ecosystems approach for international marketing. Journal of Marketing Research, 21(4), 1-20.

Axelsen, M., \& Swan, T. (2010). Designing festival experiences to influence visitor perceptions: The case of a wine and food festival. Journal of Travel Research, 49(4), 436-450.

Badgett, M., Moyce, M., \& Kleinberger, H. (2007). Turning shopper into advocates. New York, NY: IBM Institute for Business Value.

Baker, D. A., \& Crompton, J. L. (2000). Quality, satisfaction and behavioral intentions. Annals of Tourism Research, 27(3), 785-804.

Bignante, E. (2010). The use of photo-elicitation in field research: Exploring Maasai representations and use of natural resources. EchoGéo, 11. Retrieved from http:// echogeo.revues.org/11622?iframe=true \&width $=100 \% \&$ height $=100 \%$

Bitner, M. J. (1992). Servicescapes: The impact of physical surroundings on customers and employees. The Journal of Marketing, 56(2), 57-71.

Boo, S., \& Lu, X. (2015). Tourists' World Expo experiences. Event Management, 19(1), 123-142.

Bowen, H. E., \& Daniels, M. J. (2005). Does the music matter? Motivations for attending a music festival. Event Management, 9(3), 155-164.

Crowther, P., Bostock, J., \& Perry, J. (2015). Review of established methods in event research. Event Management, 19(1), 93-107.

Crowther, P., \& Donlan, L. (2011). Value-creation space: The role of events in a service-dominant marketing paradigm. Journal of Marketing Management, 27(13-14), 1444-1463.

Gentile, C., Spiller, N., \& Noci, G. (2007). How to sustain the customer experience: An overview of experience components that co-create value with the customer. European Management Journal, 25(5), 395-410.

Getz, D. (2010). The nature and scope of festival studies. International Journal of Event Management Research, 5(1), 1-47.

Getz, D. (2012). Event studies: Discourses and future directions. Event Management, 16(2), 171-187.

Getz, D. (2013). Event studies: Theory, research and policy for planned events (2nd ed.). Abingdon, UK: Routledge.
Getz, D., \& Page, S. J. (2016). Progress and prospects for event tourism research. Tourism Management, 52, 593-631.

Gupta, S., \& Vajic, M. (2000). The contextual and dialectical nature of experiences. In J. Fitzsimmons \& M. J. Fitzsimmons (Eds.), New service development: Creating memorable experiences (pp. 33-51). Thousands Oaks, CA: Sage Publication Inc.

Harper, D. (2002). Talking about pictures: A case for photo elicitation. Visual Studies, 17(1), 13-26.

Harris, M. (1976). History and significance of the emic/ etic distinction. Annual Review of Anthropology, 5(1), 329-350.

Hosany, S., \& Witham, M. (2009). Dimensions of cruisers' experiences, satisfaction, and intention to recommend. Journal of Travel Research, 49(3), 351-364.

Kim, K., Uysal, M., \& Chen, J. S. (2001). Festival visitor motivation from the organizers' points of view. Event Management, 7(2), 127-134.

Lee, Y.-K., Lee, C.-K., Lee, S.-K., \& Babin, B. J. (2008). Festivalscapes and patrons' emotions, satisfaction, and loyalty. Journal of Business Research, 61(1), 56-64.

Lett, J. (1990). Emics and etics: Notes on the epistemology of anthropology. In T. N. Headland, K. L. Pike, \& M. Harris (Eds.), Emics and etics: The insider/outsider debate (pp. 127-142). Newbury Park, CA: Sage Publications.

Li, X., \& Petrick, J. F. (2006). A review of festival and event motivation studies. Event Management, 9(4), 239-245.

Mason, M. C., \& Paggiaro, A. (2012). Investigating the role of festivalscape in culinary tourism: The case of food and wine events. Tourism Management, 33(6), 1329-1336.

Mason, P., \& Beaumont-Kerridge, J. (2004). Motivations for attendance at the 2001 Sidmouth International Festival: Fun, family, friends, fulfilment or folk. In P. Long \& R. Robinson (Eds.), Festivals and tourism: Marketing, management and evaluation (pp. 33-46). Sunderland, UK: Business Education Publishers.

Matteucci, X. (2013). Photo elicitation: Exploring tourist experiences with researcher-found images. Tourism Management, 35, 190-197.

Morgan, D. L. (1998). Practical strategies for combining qualitative and quantitative methods: Applications to health research. Qualitative Health Research, 8(3), 362-376.

Morgan, M. (2008). What makes a good festival? Understanding the event experience. Event Management, 12(2), 81-93.

Nawijn, J. (2011). Determinants of daily happiness on vacation. Journal of Travel Research, 50(5), 559-566.

Petermans, A., Kent, A., \& Van Cleempoel, K. (2014). Photoelicitation: Using photographs to read retail interiors through consumers' eyes. Journal of Business Research, 67(11), 2243-2249.

Pink, S. (2013). Doing visual ethnography. London, UK: Sage.

Polaine, A., Løvlie, L., \& Reason, B. (2013). Service design: From insight to implementation. Brooklyn, NY: Rosenfeld Media, LLC. 
Prahalad, C. K., \& Ramaswamy, V. (2004). Co-creation experiences: The next practice in value creation. Journal of Interactive Marketing, 18(3), 5-14.

Pullman, M. E., \& Robson, S. K. A. (2007). Visual methods: Using photographs to capture customers' experience with design. Cornell Hotel and Restaurant Administration Quarterly, 48(2), 121-144.

Savinovic, A., Kim, S., \& Long, P. (2012). Audience members' motivation, satisfaction, and intention to re-visit an ethnic minority cultural festival. Journal of Travel \& Tourism Marketing, 29(7), 682-694.

Scarles, C. (2010). Where words fail, visuals ignite: Opportunities for visual autoethnography in tourism research. Annals of Tourism Research, 37(4), 905-926.

Scarles, C. (2011). Eliciting embodied knowledge and response: Respondent-led photography and visual autoethnography. In T. Rakić \& D. Chambers (Eds.), An introduction to visual research methods in tourism (pp. 70-91). New York, NY: Routledge.

Schmitt, B. H. (1999). Experiential marketing. Journal of Marketing Management, 15(1-3), 53-67.

Tinkler, P. (2013). Using photographs in social and historical research. London, UK: Sage.

Van Winkle, C. M., \& Falk, J. H. (2015). Personal meaning mapping at festivals: A useful tool for a challenging context. Event Management, 19(1), 143-150.

Van Zyl, C., \& Botha, C. (2004). Motivational factors of local residents to attend the Aardklop National Arts Festival. Event Management, 8(4), 213-222.
Vargo, S. L., \& Lusch, R. F. (2004). Evolving to a new dominant logic for marketing. Journal of Marketing, 68(1), $\underline{1-17 .}$

Venkatraman, M., \& Nelson, T. (2008). From servicescape to consumptionscape: A photo-elicitation study of Starbucks in the New China. Journal of International Business Studies, 39(6), 1010-1026.

Verhoef, P. C., Lemon, K. N., Parasuraman, A., Roggeveen, A., Tsiros, M., \& Schlesinger, L. A. (2009). Customer experience creation: Determinants, dynamics and management strategies. Journal of Retailing, 85(1), 3 1-41.

Walls, A. R., Okumus, F., Wang, Y. R., \& Kwun, D. J.-W. (2011a). An epistemological view of consumer experiences. International Journal of Hospitality Management, 30(1), 10-21.

Walls, A. R., Okumus, F., Wang, Y. R., \& Kwun, D. J.-W. (2011b). Understanding the consumer experience: An exploratory study of luxury hotels. Journal of Hospitality Marketing \& Management, 20(2), 166-197.

Yuan, J. J., Cai, L. A., Morrison, A. M., \& Linton, S. (2005). An analysis of wine festival attendees' motivations: A synergy of wine, travel and special events? Journal of Vacation Marketing, 11(1), 41-58.

Yuan, J. J., \& Jang, S. S. (2007). The effects of quality and satisfaction on awareness and behavioral intentions: Exploring the role of a wine festival. Journal of Travel Research, 46(3), 279-288. 